\title{
Prevalence of Small Intestinal Bacterial Overgrowth among Chronic Pancreatitis Patients: A Case-Control Study
}

\author{
Amelie Therrien, Simon Bouchard, Sacha Sidani, and Mickael Bouin \\ Laboratoire de Neurogastroentérologie et Motricité Digestive, Service de Gastroentérologie, Hôpital Saint-Luc, \\ Centre de Recherche du Centre Hospitalier de l'Université de Montréal (CRCHUM), Montréal, QC, Canada H2X 3J4
}

Correspondence should be addressed to Amelie Therrien; amelie.therrien.3@umontreal.ca

Received 14 June 2015; Accepted 18 November 2015

Copyright (C) 2016 Amelie Therrien et al. This is an open access article distributed under the Creative Commons Attribution License, which permits unrestricted use, distribution, and reproduction in any medium, provided the original work is properly cited.

\begin{abstract}
Background. Patients with chronic pancreatitis (CP) exhibit numerous risk factors for the development of small intestinal bacterial overgrowth (SIBO). Objective. To determine the prevalence of SIBO in patients with CP. Methods. Prospective, single-centre casecontrol study conducted between January and September 2013. Inclusion criteria were age 18 to 75 years and clinical and radiological diagnosis of CP. Exclusion criteria included history of gastric, pancreatic, or intestinal surgery or significant clinical gastroparesis. SIBO was detected using a standard lactulose breath test (LBT). A healthy control group also underwent LBT. Results. Thirty-one patients and 40 controls were included. The patient group was significantly older (53.8 versus 38.7 years; $P<0.01$ ). The proportion of positive LBTs was significantly higher in CP patients (38.7 versus $2.5 \%: P<0.01$ ). A trend toward a higher proportion of positive LBTs in women compared with men was observed ( 66.6 versus $27.3 \% ; P=0.056)$. The subgroups with positive and negative LBTs were comparable in demographic and clinical characteristics, use of opiates, pancreatic enzymes replacement therapy (PERT), and severity of symptoms. Conclusion. The prevalence of SIBO detected using LBT was high among patients with CP. There was no association between clinical features and the risk for SIBO.
\end{abstract}

\section{Introduction}

Small intestinal bacterial overgrowth (SIBO) is defined as the presence of $>10^{5}$ bacteria/mL in the small bowel, most of which are enterobacteria from the colonic flora [1]. Such overgrowth can cause malabsorption and maldigestion, which subsequently leads to diarrhea, steatorrhea, bloating, chronic pain, and vitamin $B_{12}$ deficiency [1]. The main risk factors for SIBO include conditions associated with stasis of intestinal content due to structural abnormalities or dysmotility [1-6] as well as conditions associated with achlorhydria $[1,2]$. There is controversy regarding the possibility of an association between SIBO and the use of proton pump inhibitors [1, 2 , 7]. Moreover, SIBO may represent both a cause and a consequence of slow intestinal transit $[8,9]$.

Chronic pancreatitis (CP) is a cause of abdominal pain, steatorrhea, and malabsorption and can lead to significant narcotic use [10]. Many factors are associated with both $\mathrm{CP}$ and SIBO, especially alcohol and narcotic use, intestinal dysmotility, and pancreatic enzyme deficiency [11]. It is hypothesized that pancreatic enzymes have antimicrobial properties and modify the intestinal chyme $[12,13]$ and that a deficiency leads to SIBO. Although previous studies have suggested a high incidence of SIBO in patients with $\mathrm{CP}$ $[1,14-17]$, small sample size and confounding factors, such as narcotic use and history of gastroduodenal surgery (with or without vagotomy), render a direct association between $\mathrm{CP}$ and SIBO difficult [13-17].

We hypothesized that there is a high prevalence of SIBO in patients with $\mathrm{CP}$, which may contribute to the chronicity of diarrhea and bloating. The aim of the present study was to determine the prevalence of SIBO among patients with CP. Second, due to the similarities in the clinical presentation of these two diseases, we also sought to identify more specific clinical factors for SIBO among patients with CP.

\section{Methods}

A prospective case-control study was performed between January and September 2013 at the digestive motility laboratory of the Centre Hospitalier de l'Université de Montréal 
(Montreal, Quebec). The study protocol was approved by the Ethics Committee of the institution on January 8, 2013. Informed written consent was obtained from all patients.

2.1. Patients. Patients with CP who were followed up by a gastroenterologist or a hepatobiliary surgeon in the authors' tertiary-care centre were recruited.

2.2. Inclusion Criteria. Patients between 18 and 75 years of age with a confirmed diagnosis of CP were included in the present study. Diagnosis was documented with either an abdominal computed tomodensitometry (according to Cambridge criteria [18]), a magnetic resonance imaging (MRI), or an endoscopic ultrasound (Rosemont criteria [19]). Patients $>75$ years of age, without diagnostic imaging documentation, who had gastroparesis or severe diabetes or were unable to fast before the lactulose breath test (LBT) were excluded. Patients with a history of gastric, intestinal, or pancreatic surgery (except appendectomy and cholecystectomy) as well as patients who underwent antibiotic therapy in the past month were also excluded. Patients taking prokinetic agents, probiotics, or laxatives were asked to discontinue the medications at least seven days before the test.

2.3. Control Group. The control group consisted of 40 healthy subjects between 18 and 75 years of age who agreed to undergo an LBT. Exclusion criteria were current chronic disease, a history of intestinal resection, or having taken any medication in the two weeks preceding the test. Every healthy subject provided written consent.

2.4. $L B T$. The LBT is a standardized and validated test to determine the presence of SIBO and to calculate intestinal transit time [20]. Lactulose is a sugar that is not absorbed in the intestine and becomes fermented by colonic bacteria after ingestion. An early production of hydrogen in the first $90 \mathrm{~min}$ is considered to be the result of fermentation by small bowel bacteria [20]. Some patients have methanogenic bacterial flora and, thus, measurements of methane are also performed [20-22].

Participants were required to fast for at least $8 \mathrm{~h}$ before the breath test and had to follow a special diet the day before (FODMAP diet without fiber, nonfermentable carbohydrates, and lactose). Smoking within $2 \mathrm{~h}$ of the test was prohibited.

The participants were instructed to blow into a Quintron 12i (QuinTron Instrument Company, Inc., USA) bag after washing their mouth with a solution of chlorhexidine $0.12 \%$ to eliminate oral flora bacteria. The hydrogen, methane, and carbon dioxide concentration (in parts per million (ppm)) were analysed using a MicroLyser Plus (QuinTron Instrument Company, Inc., USA). Subjects with an initial hydrogen value $>20$ ppm were invited to repeat the test at a later date and asked again about their diet and smoking before the test. The remainder of the participants were then given $10 \mathrm{~g}$ of lactulose to swallow. Measurements of expired gas were taken every $15 \mathrm{~min}$ for the following $3 \mathrm{~h}$.

Test results that were considered to be positive for SIBO included an increase in hydrogen concentration $>20 \mathrm{ppm}$ over the baseline value in the first $90 \mathrm{~min}$, two consecutives peaks $>13$ ppm noted, one of which occurring before $90 \mathrm{~min}$, and two tests with a baseline hydrogen value $>20 \mathrm{ppm}$, if the patient was deemed reliable on having followed the diet before the test [23-25]. Every hydrogen value was corrected by the device according to the dead space (exhaled carbon dioxide measurement).

2.5. Data Collection. A chart review was performed to collect patient clinical data. A standardized questionnaire was completed by the patients the day of the breath test. This questionnaire explored patient demographics, medical and surgical history, medication use, and recent gastrointestinal symptoms and their severity. The symptom inquiry was based on the gastrointestinal symptom score used for functional dyspepsia [25]. Symptoms specific to CP were added [10]. A scale of 0 to 4 was used to grade symptom severity, with a score of 3 or 4 considered to be severe. Narcotic use was graded from occasional use during pain exacerbations to regular intake; use in the $24 \mathrm{~h}$ preceding the test was also documented. A score using the M-ANNHEIM severity index was calculated for each participant. The latter is one of the most recent scoring systems incorporating clinical parameters such as pain, severe complications, pancreatic exocrine, and endocrine insufficiency as well as pancreas morphology based on the Cambridge classification [18]. Finally, demographic data and body mass index of the healthy control subjects were collected on the day of the breath test.

2.6. Statistical Analysis. Considering an expected prevalence of SIBO of $2 \%$ to $5 \%$ in the control group and $35 \%$ to $50 \%$ in patients, it was estimated that 25 to 30 patients with $\mathrm{CP}$ were required to achieve significance and adequately test for a difference in the prevalence of SIBO between CP patients and the 40 healthy controls $[1,14,15,17]$. A comparative analysis of the demographic and clinical data was performed between the two groups. The aim of this analysis was to determine whether certain clinical characteristics predispose to SIBO. Fisher's exact test was used for this statistical analysis. Finally, the $t$-test was used to compare the means of hydrogen concentration at every measurement time between the $\mathrm{CP}$ and control groups. It was also used for the comparison of the elapsed mean times before reaching a colonic peak, being defined as the first increase in hydrogen $>20 \mathrm{ppm}$ over the baseline, if happening after $90 \mathrm{~min}$, or a second increase $>20 \mathrm{ppm}$ in the event of a first peak before $90 \mathrm{~min}$.

\section{Results}

3.1. Participant Characteristics. Forty CP patients and 40 controls were evaluated. Nine patients with CP were excluded because of lack of cooperation during the protocol $(n=2)$ or due to unwillingness to repeat the test a second time after an initial breath test result $>20 \mathrm{ppm}(n=7)$. Thus, 31 patients with CP were included in the study. Their clinical characteristics are summarized in Table 1. Compared with the control group, CP patients were significantly older (53.8 
TABLE 1: Characteristics of patients with chronic pancreatitis (CP) and comparison between groups with positive $(+)$ and negative $(-)$ lactulose breath test (LBT).

\begin{tabular}{|c|c|c|c|c|}
\hline & $\begin{array}{c}\mathrm{CP} \\
(n=31)\end{array}$ & $\begin{array}{c}\mathrm{LBT}+ \\
(n=12)\end{array}$ & $\begin{array}{l}\text { LBT- } \\
(n=19)\end{array}$ & $\begin{array}{c}P \\
(\mathrm{LBT}+\mathrm{vs} \\
\text { LBT-) }\end{array}$ \\
\hline Female sex & 29.0 & 50.0 & 16.8 & 0.056 \\
\hline $\begin{array}{l}\text { Age, years, mean } \\
\pm \mathrm{SD}\end{array}$ & 53.8 & $55.1 \pm 17.2$ & $53.4 \pm 12.1$ & 0.68 \\
\hline Caucasian & 80.7 & 75.0 & 84.2 & 0.38 \\
\hline Active smokers & 32.3 & 33.3 & 31.6 & 0.99 \\
\hline Active alcohol use & 35.0 & 33.3 & 36.8 & 0.99 \\
\hline $\begin{array}{l}\text { Alcohol-related } \\
\mathrm{CP}\end{array}$ & 41.9 & 50.0 & 36.8 & 0.71 \\
\hline Idiopathic CP & 32.3 & 33.3 & 31.6 & 0.99 \\
\hline Celiac disease & 3.2 & 8.3 & 0 & - \\
\hline $\begin{array}{l}\text { BMI overweight } \\
\text { or obese }\end{array}$ & 48.4 & 58.2 & 42.0 & 0.47 \\
\hline Radiation therapy & 6.0 & 8.3 & 5.3 & 0.99 \\
\hline $\begin{array}{l}\text { Insulin- } \\
\text { dependent } \\
\text { diabetes }\end{array}$ & 12.9 & 8.3 & 15.8 & 0.99 \\
\hline $\begin{array}{l}\text { Cirrhosis (Child } \\
\text { Pugh A) }\end{array}$ & 16.1 & 25.0 & 10.5 & 0.35 \\
\hline Cholecystectomy & 19.4 & 25.0 & 15.8 & 0.65 \\
\hline Hepatic steatosis & 32.0 & 16.7 & 42.1 & 0.24 \\
\hline
\end{tabular}

Data is presented as \% unless otherwise indicated. BMI: body mass index; vs: versus.

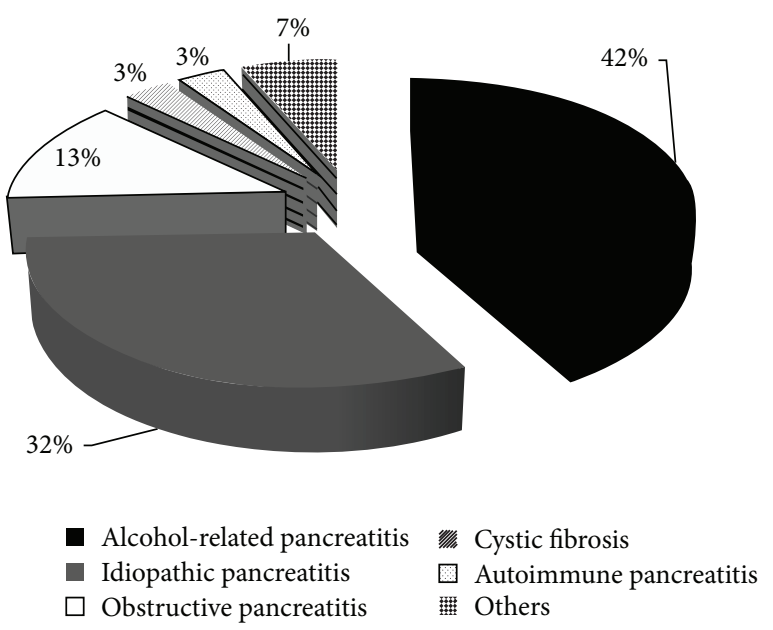

FIGURE 1: Etiology of chronic pancreatitis.

years versus 38.7 years; $P<0.01)$ and included fewer women (29.0\% versus $87.5 \% ; P<0.01)$.

3.2. Clinical Characteristics of CP Patients. The different causes of pancreatitis in the CP group are presented in Figure 1 . The etiology of CP was alcohol in $42 \%$ of the patients. The clinical manifestations and/or symptoms are presented in Table 2. The imaging modality used for diagnosis of $\mathrm{CP}$
TABLE 2: Clinical manifestations in patients with chronic pancreatitis (CP) and positive (+) and negative (-) lactulose breath test (LBT).

\begin{tabular}{lcccc}
\hline $\begin{array}{l}\text { Clinical } \\
\text { manifestation }\end{array}$ & $\begin{array}{c}\text { CP } \\
(n=31)\end{array}$ & $\begin{array}{c}\text { LBT+ } \\
(n=12)\end{array}$ & $\begin{array}{c}\text { LBT- } \\
(n=19)\end{array}$ & $\begin{array}{c}P \\
\text { (LBT+ vs } \\
\text { LBT- })\end{array}$ \\
\hline $\begin{array}{l}\text { Abdominal } \\
\text { cramping }\end{array}$ & $67.7(25.8)$ & $83.3(41.7)$ & $57.9(15.8)$ & 0.24 \\
$\begin{array}{l}\text { Dyspepsia } \\
\text { GERD, \% }\end{array}$ & $61.3(16.1)$ & $75.0(25.0)$ & $52.6(10.5)$ & 0.27 \\
Bloating & 48.4 & 58.3 & 42.1 & 0.47 \\
Constipation & $44.8(13.9)$ & $50.0(25.0)$ & $47.4(5.3)$ & 0.99 \\
Epigastric pain & $41.9(22.6)$ & $50.0(33.3)$ & $36.8(15.8)$ & 0.71 \\
Chest pain, \% & 38.7 & 50.0 & 31.6 & 0.45 \\
Early satiety, \% & 38.7 & 41.7 & 36.8 & 0.99 \\
Steatorrhea, \% & 35.5 & 41.7 & 31.6 & 0.71 \\
Anorexia, \% & 35.5 & 41.7 & 31.6 & 0.71 \\
Diarrhea, \% & 9.7 & 16.7 & 21.1 & 0.99 \\
\hline
\end{tabular}

Data is presented as \% (\% severe symptoms) unless otherwise indicated. GERD: gastroesophageal reflux disease; vs: versus.

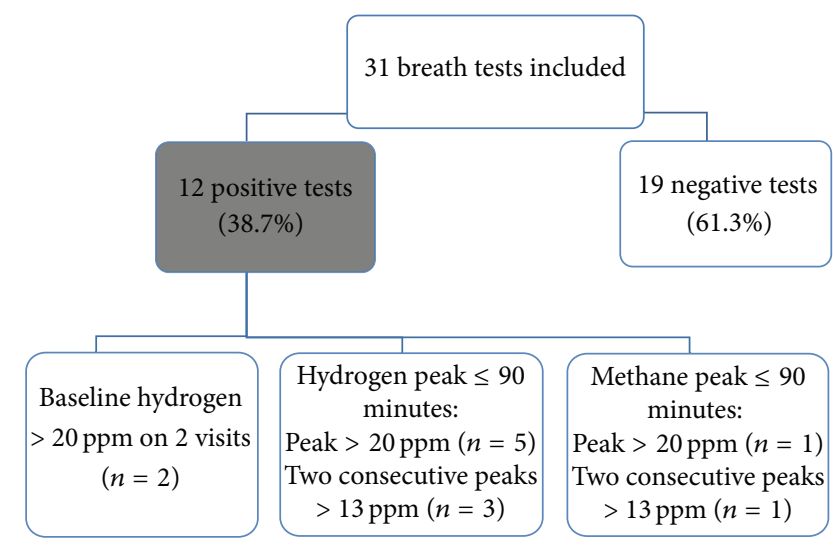

FIgURE 2: Breath test results of patients with chronic pancreatitis, ppm: parts per million.

was endoscopic ultrasound in 17 patients, abdominal computed tomography in 10, and abdominal magnetic resonance imaging in four. Regular medication taken by CP patients was as follows: $52.0 \%$ taking a proton pump inhibitor, $51.6 \%$ prescribed pancreatic enzyme replacement therapy, $22.6 \%$ taking narcotics, $12.9 \%$ using prokinetic agents, and $3.1 \%$ using probiotics. Based on the M-ANNHEIM severity index, clinical severity of the pancreatitis was considered to be minor for 14 patients, increased for 11, advanced for four, and marked for two [18].

3.3. LBTs. The test was suggestive of bacterial overgrowth in 12 patients. The numbers of positive test results according to each positivity criterion with hydrogen and methane are presented in Figure 2. The LBT was well tolerated and the only adverse event was diarrhea during the test in one patient (LBT negative for SIBO). 


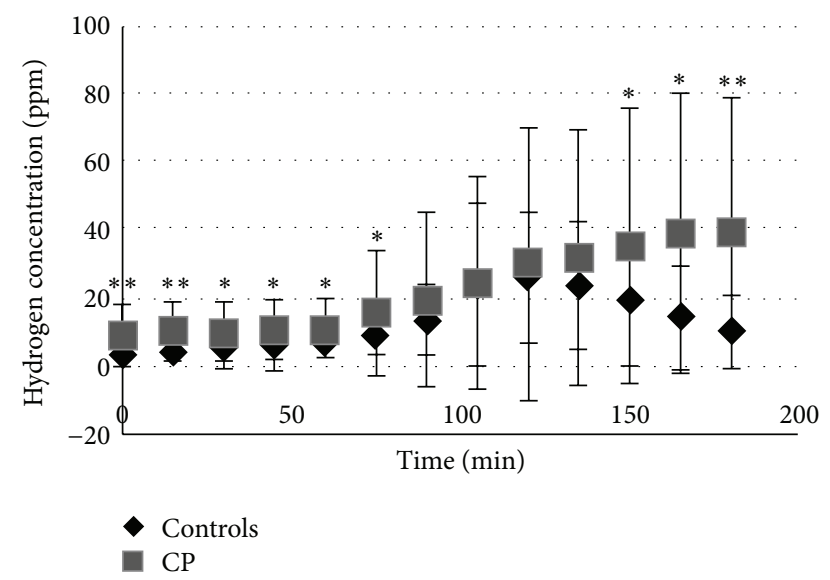

FIgURE 3: Mean \pm SD values of exhaled hydrogen concentration (parts per million (ppm)) during lactulose breath test (LBT). Comparison of the mean curves and SD of exhaled hydrogen concentration of LBT between chronic pancreatitis (CP) patients and controls; ${ }^{*} P<0.05 ;{ }^{* *} P<0.0001$.

The prevalence of positive LBT was significantly higher in the CP patients group compared with the control group (38.7 versus $2.5 \% ; P<0.01$ ). A comparison of the mean values for $\mathrm{CP}$ patients and controls is shown in Figure 3. Baseline hydrogen values were significantly higher for the $\mathrm{CP}$ patients compared with controls $(9.2 \pm 8.9$ versus $2.8 \pm 2.2$ ppm; $P<0.001$ ). In fact, most of the time, mean hydrogen values were significantly higher in the $\mathrm{CP}$ group compared with the control group (Figure 3). Finally, the time lapse required to reach a colonic peak was also significantly longer in the CP patients compared with controls $(131.1 \pm 31.6 \mathrm{~min}$ versus $108.2 \pm 20.6 \mathrm{~min} ; P=0.0043$ ).

Tables 1 and 2 compare patients with a positive LBT with those with a negative LBT. The subgroups were comparable in terms of age, lifestyle, body mass index, etiology of $\mathrm{CP}$, and symptom severity, including the M-ANNHEIM severity index. However, the two patients with the highest scores (MANNHEIM index $=16$ ) had positive LBT. No statistically significant difference was found for the use of proton pump inhibitors (50.0\% versus 52.6\%; $P=0.99)$, narcotics $(25.0 \%$ versus $21.1 \% ; P=0.99$ ), and pancreatic enzyme replacement therapy $(58.3 \%$ versus $47.4 \% ; P=0.72)$. Among the group of patients with $\mathrm{CP}$, a trend toward an increased proportion of positive LBT in women was observed (66.6\% versus $27.3 \%$; $P=0.056)$.

\section{Discussion}

LBT was positive for $38.5 \%$ of patients with CP. To our knowledge, the present study was one of the largest to evaluate the prevalence of SIBO in CP in patients who did not undergo any previous gastric, pancreatic, or intestinal surgery. The prevalence of SIBO in our study was similar to that reported in previous studies, ranging between $22 \%$ and $67 \%[1,13-15,17]$. One recent study investigating hydrogen and methane excretion measured by LBT reported a prevalence of $47.2 \%$ [26].
Two other recent studies using glucose breath test found a prevalence of $14.7 \%$ and $21 \%[27,28]$.

To our knowledge, the present study was one of the few to report the prevalence of a methanogenic flora in a population with CP (present in $6.5 \%$ of patients). A recent study, using less stringent positivity criteria, also reported a prevalence of $5.9 \%$ of positive LBT only with methane and $29.4 \%$ of positive tests with both methane and hydrogen. Some tendency for hard stools and straining was observed in those patients [26]. Other studies reported that the production of methane was associated with slow intestinal transit and could present clinically with constipation [29-31]. Fifty percent of our patients who produced methane had also noted constipation.

The positivity thresholds of LBT and their sensitivity and specificity are highly inconsistent, ranging from $17 \%$ to $68 \%$ and $44 \%$ to $86 \%$, respectively [32]. LBT is based on the assumption that standard intestinal transit time is approximatively $90 \mathrm{~min}$ and that a peak of the concentration of hydrogen or methane would indicate that the lactulose has reached the colonic bacteria. However, even with strict guidance regarding diet and avoidance of some medications, test results can be influenced by several factors, notably slow transit (with no peak at all over a $3 \mathrm{~h}$ period) or fast transit, implying that an early peak would represent a "colonic peak" and not SIBO. Moreover, up to $27 \%$ of healthy subjects do not show any peak during the test $[33,34]$. In our cohort, nine (29.0\%) CP patients and $12(30.0 \%)$ controls did not show any peak in hydrogen excretion. However, among these $\mathrm{CP}$ patients, two showed an increased baseline hydrogen value and one showed increased methane production.

Nevertheless, an increase in the hydrogen or methane concentration of $20 \mathrm{ppm}$ in the first $90 \mathrm{~min}$ is used in many studies and is a validated criterion $[35,36]$. To increase the specificity of the LBT, we chose to increase the threshold to two consecutive increases of $13 \mathrm{ppm}$, which would correspond approximatively to a specificity of $86 \%$ according to a recent study [37].

Our results are similar to those from Kim et al. [26] and others $[27,28]$, demonstrating higher rates of positive LBT tests compared with other studies using the glucose breath test. Although the glucose breath test is potentially more specific than LBT (up to 83\%) [23], because of the rapid absorption of glucose in the jejunum, the LBT has also been hypothesized to be more sensitive for ileal bacterial overgrowth, which cannot be correlated with the results of jejunal aspiration (gold standard) [38]. Despite all the pitfalls of the LBT and the lack of consensus regarding the cut-off points when compared with jejunal aspiration, this test has the advantages of being noninvasive, inexpensive, and safe for the patient and enables immediate interpretation.

$\mathrm{CP}$ appears to be associated with slow intestinal transit due to the use of narcotics or the effects of maldigestion on antroduodenal motility [39, 40]. Maldigestion is likely to increase the release of peptide YY by the ileum and inhibits jejunal motility. This "ileal brake" is described in tropical sprue, celiac disease, and CP but appears to be reversible in the latter with pancreatic enzyme replacement therapy [39, 41-44]. The higher baseline hydrogen value and the delayed time for a colonic peak in our CP patients 
may corroborate this hypothesis of slower intestinal transit. Although a significant proportion of our CP patients were on pancreatic enzyme replacement therapy, we did not find a difference in the number of positive tests or in the delay before the first peak between subgroups with and without pancreatic enzyme replacement therapy. The same was true for subgroup analysis of patients with diarrhea. These observations may suggest a lack of impact of exocrine pancreatic insufficiency in our cohort, although fat malabsorption was not measured.

No patient characteristic was predictive of the presence of SIBO, except for a possible association with female sex. This can be explained by the small size of our groups. Both CP and SIBO have similar clinical presentations, which could account for the absence of significant difference in the prevalence and severity of digestive symptomatology between groups with and without positive LBT. However, there was a trend toward more severe symptoms in the positive LBT group; both participants with the highest M-ANNHEIM score were in the LBT-positive group. Kim et al. [26] reported additional significant symptoms in their LBT-positive group, which included hydrogen and methane testing.

One possible limitation of the present study was the disparity in sex and age between the case and control groups. Although the control group was significantly younger and had more women than the CP group, we do not believe older age (mean age 53.8 years) was an important confounding factor because the risk for SIBO appears to increase mostly after 75 years of age [3, 45-47]. Furthermore, there were no age differences between our groups with positive and negative LBT. Although the diagnosis of CP was made using several imaging modalities, each may lead to a probable or definite diagnosis of CP according to specific characteristics [48]. Finally, CP rarely presents alone and many of our patients had other potential causes of SIBO including excessive alcohol intake [49], diabetes [50], celiac disease [51], cystic fibrosis [52], and cirrhosis [53] (Table 1). This, however, remains representative of the real population of $\mathrm{CP}$ patients.

\section{Conclusion}

A significant proportion of LBTs were positive in our population with CP compared with the control group, which is suggestive of SIBO. The effects of the treatment of SIBO on pain and pancreatic insufficiency remain to be studied.

\section{Competing Interests}

The authors have no financial disclosures nor competing interests to declare.

\section{Acknowledgments}

The authors thank Dr. Maya Nader and Mrs. Marwa Bsat for proofreading the paper draft. The authors also thank the following doctors and the CHUM Gastoenterology and Hepatobiliary Surgery Units for their help in recruiting participants: Dr. Raymond Lahaie, Dr. Michel Lemoyne, Dr. Benoit-Pierre Panzini, Dr. Judy Dorais, Dr. Anand V. Sahai,
Dr. Sarto Paquin, Dr. Audrey Weber, Dr. Yves Caussignac, Dr. Louise Daoust, Dr. André Roy, Dr. Frank VandenbrouckeMenu, and Dr. Marc Bilodeau. Special thanks are due to Mme. Josette Joubert for her technical support.

\section{References}

[1] R. S. Choung, K. C. Ruff, A. Malhotra et al., "Clinical predictors of small intestinal bacterial overgrowth by duodenal aspirate culture," Alimentary Pharmacology and Therapeutics, vol. 33, no. 9, pp. 1059-1067, 2011.

[2] S. J. Lewis, S. Franco, G. Young, and S. J. D. O'Keefe, “Altered bowel function and duodenal bacterial overgrowth in patients treated with omeprazole," Alimentary Pharmacology and Therapeutics, vol. 10, no. 4, pp. 557-561, 1996.

[3] S. M. Riordan, C. J. McIver, D. Wakefield, T. D. Bolin, V. M. Duncombe, and M. C. Thomas, "Small intestinal bacterial overgrowth in the symptomatic elderly," The American Journal of Gastroenterology, vol. 92, no. 1, pp. 47-51, 1997.

[4] S. V. Rana and S. B. Bhardwaj, "Small intestinal bacterial overgrowth," Scandinavian Journal of Gastroenterology, vol. 43, no. 9, pp. 1030-1037, 2008.

[5] S. Rose, M. A. Young, and J. C. Reynolds, "Gastrointestinal manifestations of scleroderma," Gastroenterology Clinics of North America, vol. 27, no. 3, pp. 563-594, 1998.

[6] E. Husebye, V. Skar, T. Høverstad, T. Iversen, and K. Melby, "Abnormal intestinal motor patterns explain enteric colonization with gram-negative bacilli in late radiation enteropathy," Gastroenterology, vol. 109, no. 4, pp. 1078-1089, 1995.

[7] S. K. Ratuapli, T. G. Ellington, M.-T. O’Neill et al., "Proton pump inhibitor therapy use does not predispose to small intestinal bacterial overgrowth," American Journal of Gastroenterology, vol. 107, no. 5, pp. 730-735, 2012.

[8] P. G. Justus, A. Fernandez, J. L. Martin, C. E. King, P. P. Toskes, and J. R. Mathias, "Altered myoelectric activity in the experimental blind loop syndrome," Journal of Clinical Investigation, vol. 72, no. 3, pp. 1064-1071, 1983.

[9] M. Pimentel, E. E. Soffer, E. J. Chow, Y. Kong, and H. C. Lin, "Lower frequency of MMC is found in IBS subjects with abnormal lactulose breath test, suggesting bacterial overgrowth," Digestive Diseases and Sciences, vol. 47, no. 12, pp. 2639-2643, 2002.

[10] K. Mergener and J. Baillie, "Chronic pancreatitis," The Lancet, vol. 350, no. 9088, pp. 1379-1385, 1997.

[11] I. D. Van Felius, L. M. A. Akkermans, K. Bosscha et al., "Interdigestive small bowel motility and duodenal bacterial overgrowth in experimental acute pancreatitis," Neurogastroenterology and Motility, vol. 15, no. 3, pp. 267-276, 2003.

[12] E. Rubinstein, Z. Mark, J. Haspel et al., "Antibacterial activity of the pancreatic fluid," Gastroenterology, vol. 88, no. 4, pp. 927932, 1985.

[13] N. B. Gubergrits, Y. V. Linevskiy, G. M. Lukashevich, P. G. Fomenko, T. V. Moroz, and T. Mishra, "Morphological and functional alterations of small intestine in chronic pancreatitis," Journal of the Pancreas, vol. 13, no. 5, pp. 519-528, 2012.

[14] F. Casellas, L. Guarner, E. Vaquero, M. Antolín, X. De Gracia, and J.-R. Malagelada, "Hydrogen breath test with glucose in exocrine pancreatic insufficiency," Pancreas, vol. 16, no. 4, pp. 481-486, 1998.

[15] E. Trespi and A. Ferrieri, "Intestinal bacterial overgrowth during chronic pancreatitis," Current Medical Research and Opinion, vol. 15, no. 1, pp. 47-52, 1999. 
[16] C. Mancilla A, A. M. Madrid S, C. Hurtado H et al., "Small intestine bacterial overgrowth in patients with chronic pancreatitis," Revista Médica de Chile, vol. 136, no. 8, pp. 976-980, 2008.

[17] B. Lembcke, B. Kraus, and P. G. Lankisch, "Small intestinal function in chronic relapsing pancreatitis," HepatoGastroenterology, vol. 32, no. 3, pp. 149-151, 1985.

[18] A. Schneider, J. M. Löhr, and M. V. Singer, "The M-ANNHEIM classification of chronic pancreatitis: introduction of a unifying classification system based on a review of previous classifications of the disease," Journal of Gastroenterology, vol. 42, no. 2, pp. 101-119, 2007.

[19] M. F. Catalano, A. Sahai, M. Levy et al., "EUS-based criteria for the diagnosis of chronic pancreatitis: the Rosemont classification," Gastrointestinal Endoscopy, vol. 69, no. 7, pp. 1251-1261, 2009.

[20] A. Gasbarrini, G. R. Corazza, G. Gasbarrini et al., "Methodology and indications of $\mathrm{H}_{2}$-breath testing in gastrointestinal diseases: the Rome Consensus Conference," Alimentary Pharmacology \& Therapeutics, vol. 29, supplement 1, pp. 1-49, 2009.

[21] Y. Peled, T. Gilat, E. Liberman, and Y. Bujanover, “The development of methane production in childhood and adolescence," Journal of Pediatric Gastroenterology and Nutrition, vol. 4, no. 4, pp. 575-579, 1985.

[22] A. P. M. Kerckhoffs, M. R. Visser, M. Samsom et al., "Critical evaluation of diagnosing bacterial overgrowth in the proximal small intestine," Journal of Clinical Gastroenterology, vol. 42, no. 10, pp. 1095-1102, 2008.

[23] G. R. Corazza, M. G. Menozzi, A. Strocchi et al., "The diagnosis of small bowel bacterial overgrowth. Reliability of jejunal culture and inadequacy of breath hydrogen testing," Gastroenterology, vol. 98, no. 2, pp. 302-309, 1990.

[24] G. Corazza, A. Strocchi, M. Sorge, G. Benati, and G. Gasbarrini, "Prevalence and consistency of low breath H2 excretion following lactulose ingestion. Possible implications for the clinical use of the H2 breath test," Digestive Diseases and Sciences, vol. 38, no. 11, pp. 2010-2016, 1993.

[25] B. Adam, T. Liebregts, K. Saadat-Gilani, B. Vinson, and G. Holtmann, "Validation of the gastrointestinal symptom score for the assessment of symptoms in patients with functional dyspepsia," Alimentary Pharmacology and Therapeutics, vol. 22, no. 4, pp. 357-363, 2005.

[26] D. B. Kim, C.-N. Paik, H. J. Sung et al., "Breath hydrogen and methane are associated with intestinal symptoms in patients with chronic pancreatitis," Pancreatology, vol. 15, no. 5, pp. 514$518,2015$.

[27] K. Kumar, U. C. Ghoshal, D. Srivastava, A. Misra, and S. Mohindra, "Small intestinal bacterial overgrowth is common both among patients with alcoholic and idiopathic chronic pancreatitis," Pancreatology, vol. 14, no. 4, pp. 280-283, 2014.

[28] M. Signoretti, S. Stigliano, R. Valente, M. Piciucchi, G. Delle Fave, and G. Capurso, "Small intestinal bacterial overgrowth in patients with chronic pancreatitis," Journal of Clinical Gastroenterology, vol. 48, supplement 1, pp. S52-S55, 2014.

[29] M. Pimentel, A. G. Mayer, S. Park, E. J. Chow, A. Hasan, and Y. Kong, "Methane production during lactulose breath test is associated with gastrointestinal disease presentation," Digestive Diseases and Sciences, vol. 48, no. 1, pp. 86-92, 2003.

[30] M. Pimentel, H. C. Lin, P. Enayati et al., "Methane, a gas produced by enteric bacteria, slows intestinal transit and augments small intestinal contractile activity," American Journal of Physiology-Gastrointestinal and Liver Physiology, vol. 290, no. 6, pp. G1089-G1095, 2006.
[31] D. Cloarec, F. Bornet, S. Gouilloud, J. L. Barry, B. Salim, and J. P. Galmiche, "Breath hydrogen response to lactulose in healthy subjects: relationship to methane producing status," Gut, vol. 31, pp. 300-304, 1990.

[32] R. J. Saad and W. D. Chey, "Breath testing for small intestinal bacterial overgrowth: maximizing test accuracy," Clinical Gastroenterology and Hepatology, vol. 12, no. 12, pp. 1964-1972, 2014.

[33] C. E. King and P. P. Toskes, "Comparison of the 1-gram [14C]xylose, 10-gram lactulose- $\mathrm{H} 2$, and 80 -gram glucose- $\mathrm{H} 2$ breath tests in patients with small intestine bacterial overgrowth," Gastroenterology, vol. 91, no. 6, pp. 1447-1451, 1986.

[34] A. Strocchi, M. Sorge, L. Pranzo et al., "Intraindividual variability in $\mathrm{H} 2$ production capacity," Gastroenterology International, vol. 1, article 593, 1988.

[35] B. Walters and S. J. Vanner, "Detection of bacterial overgrowth in IBS using the lactulose $\mathrm{H}_{2}$ breath test: comparison with ${ }^{14} \mathrm{C}$ D-xylose and healthy controls," The American Journal of Gastroenterology, vol. 100, no. 7, pp. 1566-1570, 2005.

[36] A. I. Sharara, E. Aoun, H. Abdul-Baki, R. Mounzer, S. Sidani, and I. Elhajj, "A randomized double-blind placebo-controlled trial of rifaximin in patients with abdominal bloating and flatulence," American Journal of Gastroenterology, vol. 101, no. 2, pp. 326-333, 2006.

[37] U. C. Ghoshal, U. Ghoshal, K. Das, and A. Misra, "Utility of hydrogen breath tests in diagnosis of small intestinal bacterial overgrowth in malabsorption syndrome, and its relationship with orocecal transit time," Indian Journal of Gastroenterology, vol. 25, no. 1, pp. 6-10, 2006.

[38] M. Simrén and P.-O. Stotzer, "Use and abuse of hydrogen breath tests," Gut, vol. 55, no. 3, pp. 297-303, 2006.

[39] M. K. Vu, J. Vecht, E. H. Eddes, I. Biemond, C. B. H. W. Lamers, and A. A. M. Masclee, "Antroduodenal motility in chronic pancreatitis: are abnormalities related to exocrine insufficiency?" American Journal of Physiology-Gastrointestinal and Liver Physiology, vol. 278, no. 3, pp. G458-G466, 2000.

[40] C.-L. Lu, C.-Y. Chen, J.-C. Luo et al., "Impaired gastric myoelectricity in patients with chronic pancreatitis: role of maldigestion," World Journal of Gastroenterology, vol. 11, no. 3, pp. 372-376, 2005.

[41] U. C. Ghoshal, U. Ghoshal, A. Ayyagari et al., "Tropical sprue is associated with contamination of small bowel with aerobic bacteria and reversible prolongation of orocecal transit time," Journal of Gastroenterology and Hepatology, vol. 18, no. 5, pp. 540-547, 2003.

[42] U. C. Ghoshal, S. Kumar, A. Misra, and G. Choudhuri, "Pathogenesis of tropical sprue: a pilot study of antroduodenal manometry, duodenocaecal transit time \& fat-induced ileal brake," Indian Journal of Medical Research, vol. 137, no. 1, pp. 6372, 2013.

[43] T. E. Adrian, A. P. Savage, A. J. Bacarese-Hamilton, K. Wolfe, H. S. Besterman, and S. R. Bloom, "Peptide YY abnormalities in gastrointestinal diseases," Gastroenterology, vol. 90, no. 2, pp. 379-384, 1986.

[44] A. Tursi, "Gastrointestinal motility disturbances in celiac disease," Journal of Clinical Gastroenterology, vol. 38, no. 8, pp. 642645, 2004.

[45] D. A. Elphick, T. S. Chew, S. E. Higham, N. Bird, A. Ahmad, and D. S. Sanders, "Small bowel bacterial overgrowth in symptomatic older people: can it be diagnosed earlier?" Gerontology, vol. 51, no. 6, pp. 396-401, 2005. 
[46] M. Mac Mahon, M. Lynch, E. Mullins et al., "Small intestinal bacterial overgrowth-an incidental finding?" Journal of the American Geriatrics Society, vol. 42, no. 2, pp. 146-149, 1994.

[47] A. Parlesak, B. Klein, K. Schecher, J. C. Bode, and C. Bode, "Prevalence of small bowel bacterial overgrowth and its association with nutrition intake in nonhospitalized older adults," Journal of the American Geriatrics Society, vol. 51, no. 6, pp. 768773, 2003.

[48] D. L. Conwell, L. S. Lee, D. Yadav et al., "American Pancreatic Association practice guidelines in chronic pancreatitis evidence-based report on diagnostic guidelines," Pancreas, vol. 43, no. 8, pp. 1143-1162, 2014.

[49] C. Bode and J. C. Bode, "Effect of alcohol consumption on the gut," Bailliere's Best Practice and Research in Clinical Gastroenterology, vol. 17, no. 4, pp. 575-592, 2003.

[50] L. Cuoco, M. Montalto, R. A. Jorizzo et al., "Eradication of small intestinal bacterial overgrowth and oro-cecal transit in diabetics," Hepato-Gastroenterology, vol. 49, no. 48, pp. 15821586, 2002.

[51] A. Rubio-Tapia, S. H. Barton, J. E. Rosenblatt, and J. A. Murray, "Prevalence of small intestine bacterial overgrowth diagnosed by quantitative culture of intestinal aspirate in celiac disease," Journal of Clinical Gastroenterology, vol. 43, no. 2, pp. 157-161, 2009.

[52] J. L. Fridge, C. Conrad, L. Gerson, R. O. Castillo, and K. Cox, "Risk factors for small bowel bacterial overgrowth in cystic fibrosis," Journal of Pediatric Gastroenterology and Nutrition, vol. 44, no. 2, pp. 212-218, 2007.

[53] C. Pande, A. Kumar, and S. K. Sarin, "Small-intestinal bacterial overgrowth in cirrhosis is related to the severity of liver disease," Alimentary Pharmacology and Therapeutics, vol. 29, no. 12, pp. 1273-1281, 2009. 


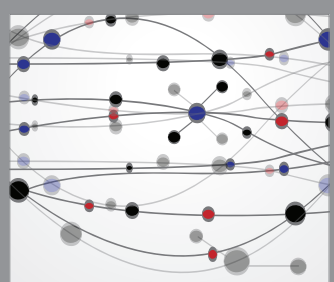

The Scientific World Journal
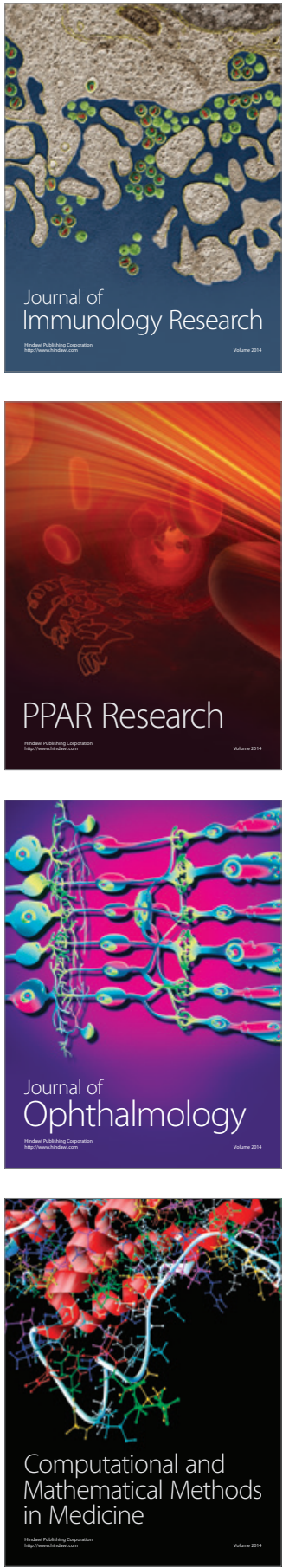

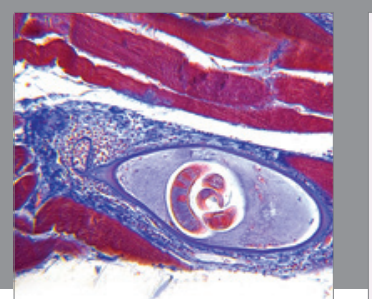

Gastroenterology Research and Practice

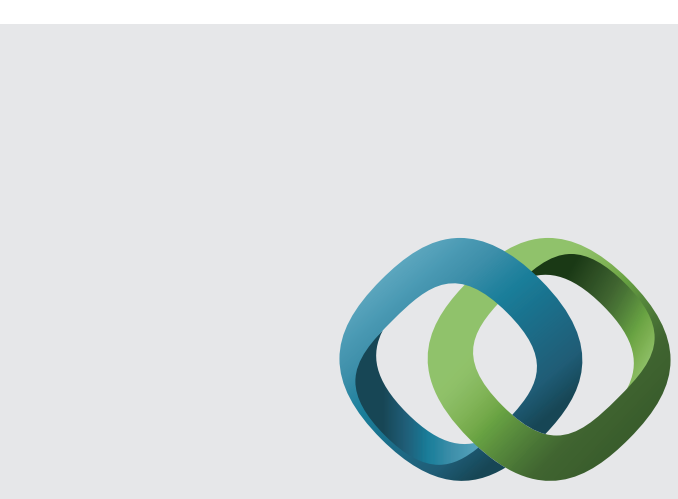

\section{Hindawi}

Submit your manuscripts at

http://www.hindawi.com
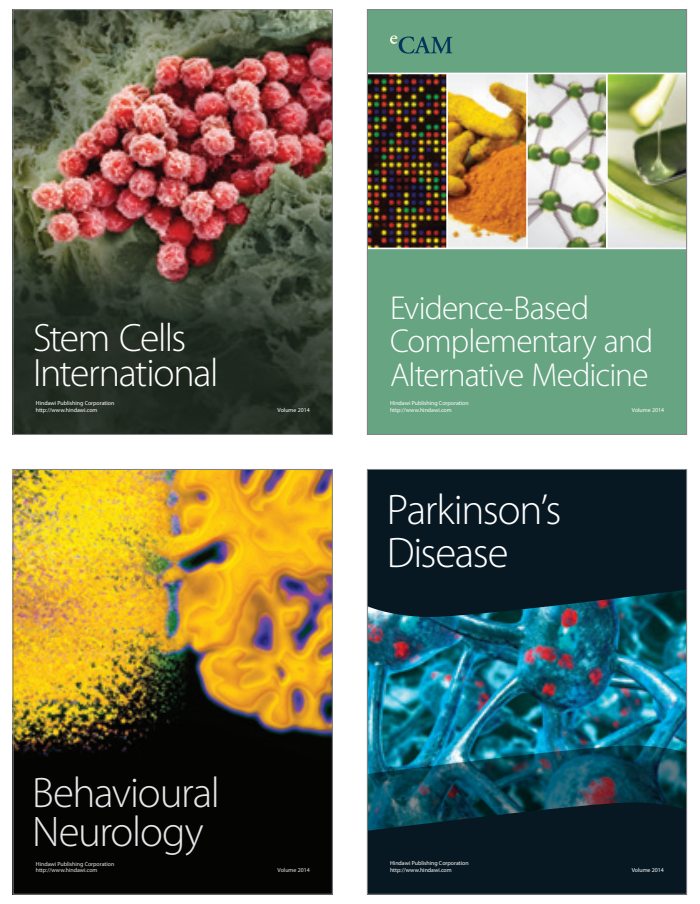
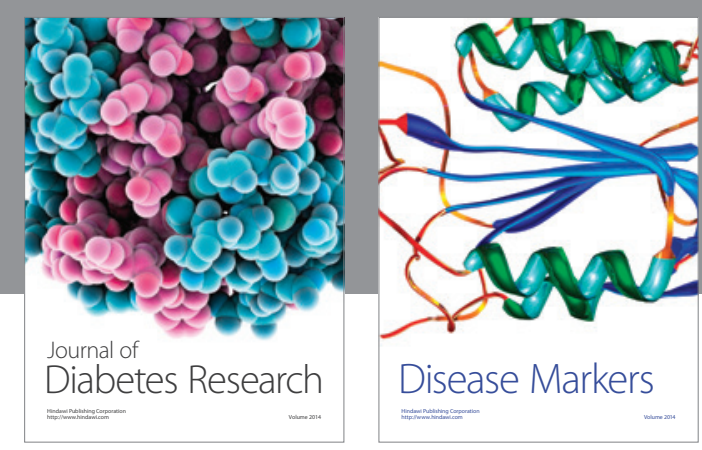

Disease Markers
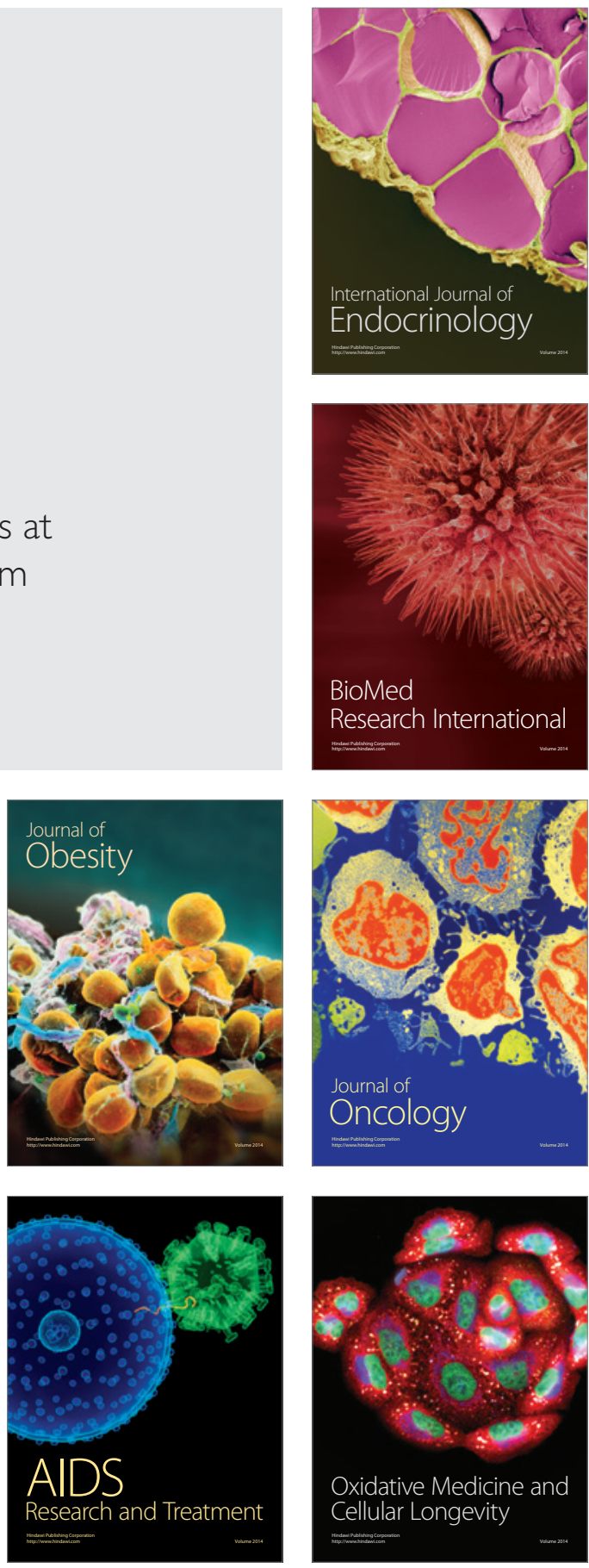